\title{
Desarrollo y reproducción de los gametófitos de dos especies chilenas de helechos, Blechnum arcuatum (Blechnaceae) y Pteris semiadnata (Pteridaceae)
}

\section{Gametophyte development and reproduction of two Chilean fern species, Blechnum arcuatum (Blechnaceae) and Pteris semiadnata (Pteridaceae)}

\author{
Andrea Seral ${ }^{1 *}$, Alejandra Flores-Bavestrelloㅇํㄹ \& José María Gabriel y Galán ${ }^{1}$ \\ 'Departamento de Biología Vegetal I, Facultad de Ciencias Biológicas, Universidad Complutense de Madrid. Avenida José \\ Antonio Nováis, 2. 28040-Madrid, España. \\ 2Laboratorio de Fisiología Vegetal, Departamento de Botánica, Facultad de Ciencias Naturales y Oceanográficas, Universidad \\ de Concepción, Casilla 160-C, Concepción, Chile. \\ *andrease@ucm.es
}

\begin{abstract}
RESUMEN
En este trabajo se estudia la germinación, el patrón de desarrollo morfológico y expresión sexual de dos especies de helechos homospóreos que habitan en Chile: Pteris semiadnata y Blechnum arcuatum. Para ello se recolectaron esporas de diferentes esporófitos y se sembraron en cultivos de agar mineral, mantenidos en condiciones controladas. Los máximos porcentajes de germinación observados fueron 82 y $91 \%$ para B. arcuatum y P. semiadnata, respectivamente. El patrón de germinación en ambas especies se corresponde con el tipo Vittaria. El patrón de desarrollo morfológico de B. arcuatum se ajusta al tipo Aspidium. Los gametófitos adultos de esta especie presentaron tricomas unicelulares por la superficie de la lámina y el margen, y se comportaron como unisexuales femeninos. Pteris semiadnata mostró un desarrollo de tipo Ceratopteris, originando gametófitos adultos glabros. En este caso, hubo tanto gametófitos bisexuales como masculinos, con un importante dimorfismo sexual en cuanto a su tamaño. La aparición previa de protalos femeninos y el fuerte dimorfismo sexual fueron indicios claros de la presencia de anteridiógeno. En ambas especies se generaron proliferaciones laminares vegetativas sobre los protalos.
\end{abstract}

Palabras clave: Anteridio, anteridiógeno, arquegonio, patrón de desarrollo morfológico, germinación.

\begin{abstract}
In this work we studied the germination, the pattern of morphological development, and the sexual expression of two homosporous ferns living in Chile: Pteris semiadnata and Blechnum arcuatum. For this purpose, spores from different sporophytes were collected, sowed on mineral agar, and kept under controlled conditions. The maximum germination percentages observed were $82 \%$ and $91 \%$ for $B$. arcuatum and $P$. semiadnata, respectively. The germination pattern in both species corresponded to the Vittaria-type. The morphological development pattern of $B$. arcuatum corresponded to the Aspidium-type. Adult gametophytes of this species presented unicellular trichomes on the surface and margin of the lamina, and they behaved as female. The species Pteris semiadnata presented a Ceratopteris-type pattern of development, originating glabrous adult prothalli. In this case, both male and bisexual gametophytes were formed, and they showed an important sexual dimorphism related to their size. The presence of female individuals at first, and the sexual dimorphism evidenced the existence of an antheridiogen system. In both species, vegetative proliferations were formed on the lamina.
\end{abstract}

KEYWORDS: Antheridium, antheridiogen, archaeogonium, pattern of morphological development, germination.

\section{INTRODUCCIÓN}

Los helechos leptosporangiados son uno de los linajes de plantas vasculares con mayor éxito biológico: sus aproximadamente diez mil especies reconocidas lo elevan al segundo grupo en biodiversidad, por detrás de las angiospermas. Son cosmopolitas, pero están especialmente bien representados en los ecosistemas lluviosos tropicales, donde pueden formar parte destacada de la biomasa vegetal. Desde el punto de vista ecológico, estas plantas ocupan 
una gran variedad de nichos: epífitos, terrícolas, saxícolas, acuáticos, etc. (Mehltreter et al. 2010). Su historia evolutiva está directamente relacionada con eventos tan relevantes como el origen de las plantas vasculares y la divergencia entre las plantas con esporas y con semillas (Vicent et al. 2014). En general, se pueden caracterizar por los tallos rizomatosos, las hojas de tipo macrófilo y los leptosporangios abaxiales.

La fase gametofítica de los helechos ha sido generalmente poco estudiada debido, entre algunas otras razones de índole práctica, a que es una fase pequeña y efímera en el ciclo de vida de estos organismos. Durante los años 60 y 70 del siglo pasado comenzó a prestarse una atención más detallada a los gametófitos. Primero desde la perspectiva de su morfología y reproducción (Atkinson \& Stokey 1964, Nayar \& Kaur 1968, 1969, 1971, Whittier 1970, Atkinson 1973), pero posteriormente destacando aspectos fisiológicos y ecológicos (Raghavan 1989, Lindsay \& Dyer 1990, Farrar et al. 2008). Así, se pone de manifiesto que los gametófitos presentan una diversidad morfológica considerable, lo que indica que los diferentes taxones pueden presentar adaptaciones específicas a diferentes tipos de hábitats, y que además pueden adoptar diversas estrategias de supervivencia (Watkins et al. 2007b). Lógicamente, la distribución y reproducción de los gametófitos dependen de numerosos factores ambientales, afectando todo ello, en último término, a la presencia de las poblaciones de los esporófitos (Warne \& Lloyd 1980). Siguiendo esta línea argumental, la investigación actual de los gametófitos trata de abordar aquellos aspectos ecofisiológicos necesarios para comprender cómo se adaptan, prosperan y se reproducen (Watkins et al. 2007a, Wada 2008). No obstante, y para poder ahondar en todos estos aspectos, sigue siendo necesario un esfuerzo previo de descripción de la morfología y la estrategia reproductiva de las aún numerosas especies, cuyo gametófito sigue siendo desconocido.

El género Blechnum L. (Blechnaceae) es un género de distribución pantropical, con unas 200 especies descritas, de las que, aproximadamente, unas 90 son americanas (Kramer et al. 1990, Kazmierczak 1999, Rolleri \& Prada 2006). Existen diversos estudios sobre los gametófitos de especies americanas de Blechnum, desde taxones mesoamericanos (Mendoza \& Pérez-García 2009) a otros del Cono Sur (Rodríguez-Ríos 1973, Durán \& de la Sota 1996, Pérez-García et al. 1996, Gabriel y Galán et al. 2008, Mendoza \& Pérez-García 2009, Rolleri et al. 2010). En general, la germinación de las esporas de las especies de Blechnum es de tipo Vittaria, mientras que el patrón de desarrollo morfológico de los gametófitos es más variable, normalmente de tipo Aspidium (Nayar \& Kaur 1971). Una característica notable de los gametófitos de Blechnum es la presencia de pelos tanto marginales como superficiales, que sin embargo faltan en algunas especies australianas (Nayar \& Kaur 1971). En Chile viven 13 especies de Blechnum, aproximadamente de la mitad, ya se han realizado estudios sobre los gametófitos (Rodríguez-Ríos 1973, Pérez-García et al. 1996). Blechnum arcuatum J. Remy crece en los bosques subantárticos de Chile y Argentina (en Chile, en bosques muy húmedos al sur del país, desde Ñuble, Provincia de Ñuble, Región del Biobío hasta Chiloé, Provincia de Chiloé, Región de Los Lagos), apareciendo en bosques, roquedales y proximidades de cursos de agua y en zonas de alta montaña (Rodríguez-Ríos 1995a).

El género Pteris L. (Pteridaceae) cuenta con aproximadamente 200 especies, de las cuales 55 se ubican en América tropical (Moran 1995). Existen numerosos trabajos en los que se ha estudiado tanto el patrón de desarrollo morfológico, como la expresión sexual de los gametófitos del género Pteris (Mendoza et al. 1997, Prada et al. 2008, Zhang et al. 2008, Martínez 2010). De estos trabajos, se pueden mencionar los siguientes caracteres como generales: el patrón de germinación de las esporas es de tipo Vittaria, mientras que el patrón de desarrollo morfológico más común es del tipo Ceratopteris, si bien existen bastantes excepciones, como son los casos de $P$. cretica L., P. multifida Poir. (Martínez 2010) y P. tripartita Sw. (Puspitasari et al. 2015). Los gametofitos de Pteris suelen ser glabros y presentar forma acorazonada. Dos características reproductivas muy interesantes que aparecen con frecuencia en las especies de Pteris son, por un lado, la presencia de anteridiógeno (Prada et al. 2008, Schneller 2008) y, por otro, la reproducción apógama (Huang et al. 2011). En Chile existen tres especies: P. berteroana C. Agardh, P. chilensis Desv. y P. semiadnata Phil., las dos primeras endémicas (Rodríguez-Ríos 1995b) y cuya fase gametofítica ha sido previamente estudiada (Mendoza et al. 1997, Letelier \& Peñailillo 2007). Pteris semiadnata es una especie nativa de Argentina y Chile, crece desde la Provincia de Concepción, Región del Biobío hasta la Provincia de Última Esperanza, Región de Magallanes y la Antártica Chilena, apareciendo también en el Archipiélago de Juan Fernández, Provincia de Valparaíso, Región de Valparaíso. Se distribuye desde el nivel del mar hasta los $1.700 \mathrm{~m}$ de altitud, preferentemente asociado a bordes de arroyos y en cerros junto a bosques y matorrales, siempre y cuando exista suficiente humedad (Rodríguez-Ríos 1995a).

El objetivo de este trabajo es el estudio de la germinación, el patrón de desarrollo morfológico y la expresión sexual de los gametófitos de dos especies de helechos chilenos, $B$. arcuatum y $P$. semiadnata, desconocidos para la ciencia.

\section{MATERIALES Y MÉTODOS}

Las muestras para realizar el estudio fueron recolectadas en el Parque Nacional Puyehue, Comuna de Puyehue, Provincia de Osorno, Región de Los Lagos, Chile, específicamente en 
la Laguna El Toro, en el camino a Antillanca (4046'14" S; $\left.72^{\circ} 16^{\prime} 14^{\prime \prime} \mathrm{W}\right), 750 \mathrm{msnm}$, repisas de roquedos en un talud, J.M. Gabriel y Galán \& A. Saldaña, agosto 2014.

Un respaldo de cada una de las especies fue depositado en el herbario MACB. Esporas de diferentes esporofitos, conservados a temperatura ambiente, se mezclaron para realizar cultivos multiespóricos en placas de Petri de 6 $\mathrm{cm}$ de diámetro que contenían agar mineral (Dyer 1979). Se sembraron un total de 6 placas, 3 por cada especie. Las esporas fueron mantenidas a una temperatura de $20 \pm 2{ }^{\circ} \mathrm{C}$ con un fotoperiodo de $18 \mathrm{~h}$ de luz. Alcanzado el estado adulto, los gametófitos se trasladaron a placas con mezcla esterilizada de tierra comercial y arena, al objeto de reducir la densidad y favorecer la reproducción.

Se consideró que las esporas germinaron, cuando de la espora surgió un primer rizoide evidente (Gabriel y Galán \& Prada 2010). Los cambios en el porcentaje de germinación a lo largo de los días se registraron contabilizando el número de esporas germinadas sobre 100 en cada una de las placas hasta que el porcentaje de germinación alcanzó un máximo y se estabilizó. Los datos de germinación que aparecen en la Figura 1, referente a los cambios de germinación a lo largo de los días realizadas para las dos especies, representan la media de las tres placas.

Para las medidas de los gametófitos se tomaron de 5-10 gametófitos por placa. Los tamaños de los protalos aparecen expresados como medias de longitud $\mathrm{x}$ ancho $\mathrm{y}$ desviación estándar. Las observaciones de las distintas fases del desarrollo y las estructuras sexuales se observaron con un microscopio Nikon LaboPhot-2, y las fotografías fueron realizadas con una cámara Nikon Coolpix MDC. Estas fotografías se realizaron tanto en preparaciones de gametófitos in vivo, como en preparaciones de gametófitos previamente teñidos con hidrato de cloral acetocarmín (Edwards \& Miller 1972).

\section{RESULTADOS}

\section{BLECHNUM ARCUATUM}

La germinación comenzó 7 días tras la siembra, registrándose ese día un porcentaje de germinación del 10,2\%. A los 22 días, el porcentaje de germinación llegó al 50,6\%. El máximo porcentaje de germinación fue de $82 \%$ y se alcanzó a los 32 días tras la siembra. La evolución en los porcentajes de germinación se muestra en la Figura 1. El modelo de germinación es de tipo Vittaria, ya que la primera célula protálica que emerge lo hace en dirección perpendicular al primer rizoide (Fig. 2A).

Por divisiones transversales de la primera célula protálica se llegó a la fase filamentosa, que se alcanzó rápidamente, pues comenzó a los 10 días tras haber realizado la siembra, y fue muy efímera. A los 11 días, la mayoría de los gametófitos se encontraban formando un filamento constituido por 2-3 células.

A partir del filamento, rápidamente se produjeron divisiones longitudinales que afectaron a todas las células del filamento y se llegó a la fase laminar. En los inicios de

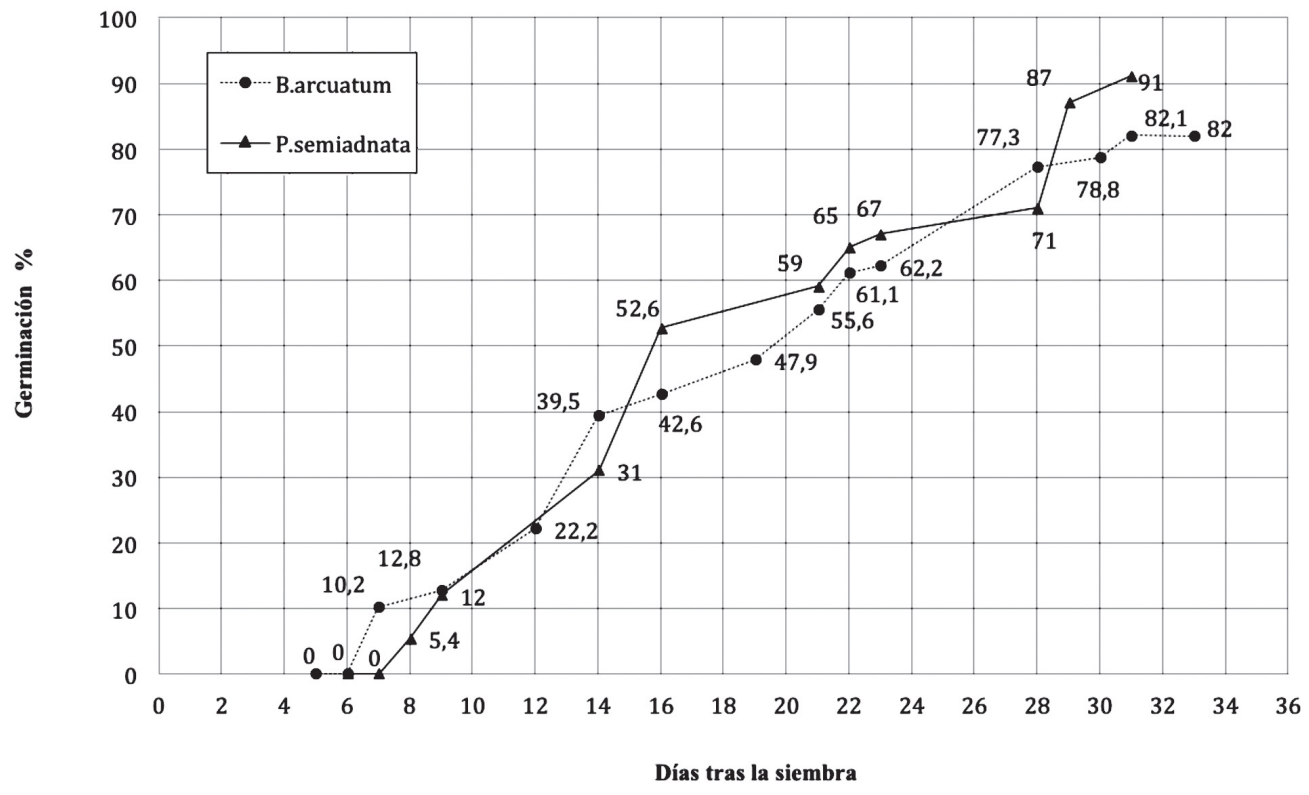

Figura 1. Cambios en el porcentaje de germinación de esporas de Blechnum arcuatum y Pteris semiadnata a lo largo de los días. Los

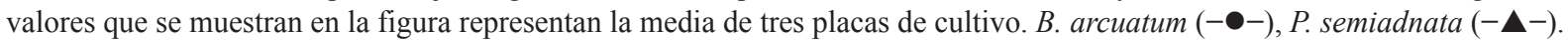

Figure 1. Changes in the percentage of spores germination of Blechnum arcuatum and Pteris semiadnata along the days. The values shown in the figure represent the mean of three Petri dishes. B. arcuatum (-๑-), P. semiadnata $(-\mathbf{\Delta}-)$. 
esta etapa, la lámina era muy pequeña y estaba constituida por 3-4 células de longitud y contaban con una superficie total de 8-13 células, con un tamaño medio de $91 \pm 20 \mathrm{x}$ $80 \pm 10 \mu \mathrm{m}$. La mayoría presentó esta forma entre los 11-17 días. En ese momento se pudo observar la diferenciación de una célula apical con forma de cuña (Fig. 2B). A lo largo de esta fase, los gametófitos fueron aumentando de tamaño. Algunos de ellos presentaron forma de espátula, y otros en esta fase adoptaron forma acorazonada. A los 21 días el 61\% de los gametófitos se encontraba en esta fase y en ellos se observó el establecimiento de un meristema pluricelular en la parte apical de la lámina, y presentaron un tamaño medio de $281 \pm 35$ × $215 \pm 25 \mu \mathrm{m}$. Hasta ese momento los gametófitos presentaban mayor longitud que anchura (Fig. 2C).

Tras 31 días el 62,3\% de los gametófitos alcanzó la fase adulta. Los gametófitos adultos presentaron tricomas unicelulares capitados localizados fundamentalmente en el margen de la lámina (Fig. 2D). También se pudieron observar algunos, aunque poco numerosos, en la superficie. Estos pelos se formaron por la división transversal de las células de la lámina. Los gametófitos cordados presexuales tenían un tamaño medio de $492 \pm 48 \times 831 \pm 150 \mu \mathrm{m}$ (Fig. 2E). Los rizoides fueron unicelulares, hialinos, y en éstos pudo observarse la acumulación del contenido celular en el ápice.

Hacia el estado de madurez reproductiva, esto es, a partir de los 33-35 días, los gametófitos desarrollaron proliferaciones vegetativas, inicialmente poco numerosas, con forma espatulada. En el transcurso de los días, dichas proliferaciones fueron haciéndose cada vez más numerosas, ocupando buena parte de la lámina del gametófito original y llegando a presentar forma cordada (Fig. 2F).

A los 33 días ya se pudo observar la aparición de arquegonios en algunos de los protalos. Una vez que los gametófitos desarrollaron arquegonios, presentaron un tamaño medio de $862 \pm 65 \times 1.725 \pm 185 \mu \mathrm{m}$. A los 59 días tras la siembra, el $81 \%$ de los gametófitos alcanzó la madurez sexual. En ese momento, todos los gametófitos sexuales observados fueron unisexuales femeninos, el resto de los gametófitos fueron estériles, no observándose la aparición de anteridios en el periodo de observación. Los arquegonios fueron típicos (Fig. 2G) y aparecieron bajo la escotadura. En cuanto al comportamiento sexual, hay que mencionar que no se percibió la aparición de esporófitos apógamos, aunque sí pudo observarse que la mayor parte de los gametófitos presentaron un engrosamiento muy prominente de la almohadilla localizada en el centro de la lámina.

\section{PTERIS SEMIADNATA}

La germinación en $P$. semiadnata comenzó 8 días tras la siembra, contabilizándose ese día un porcentaje de germinación de 5,4\%. Tras 21 días, el 59\% de las esporas habían germinado. El máximo porcentaje de germinación se registró a los 31 días. En ese momento el 91\% de las esporas habían germinado. La evolución en los porcentajes de germinación se muestra en la Figura 1. La germinación de esta especie se puede ajustar también al tipo Vittaria, dado que emerge en primer lugar un rizoide, y posteriormente una célula protálica en dirección perpendicular al mismo (Fig. 3A).

Después de 14 días tras la siembra, el 37\% de los gametófitos se encontraba en la fase filamentosa. En ese momento el filamento contaba con 2-5 células. Esta fase comenzó 10 días después de haber realizado la siembra y se prolongó durante 9 días.

Las primeras divisiones longitudinales paralelas al eje de crecimiento afectaron a las células distales, mientras que no se dieron en las células apicales y subapicales. Pronto se diferenció una célula meristemática apical y subcónica. En más de la mitad de los gametófitos pudo observarse la aparición de esta célula a los 25 días (Fig. 3B). La lámina fue creciendo hasta que finalmente se estableció un meristema pluricelular localizado en el ápice de la lámina y algo desplazado hacia el lateral (Fig. 3C). Transcurridos 24 días desde la siembra, el $48 \%$ de los gametófitos se encontraban en la fase laminar con un tamaño medio de $138,5 \pm 5 \times 241,5 \pm 15 \mu \mathrm{m}$.

En los inicios de la fase adulta, los gametófitos no presentaban forma cordada, sino que el hecho de que en la fase laminar el meristema estuviera algo desplazado hacia el lateral, hizo que los gametófitos estuvieran formados por varios lóbulos (Fig. 3D). Sin embargo, en los subsiguientes días llegaron a adoptar forma cordada, si bien algo asimétrica (Fig. 3E), con un meristema bien desarrollado en la escotadura. Tras 64 días, los gametófitos que se encontraban en fase cordada presentaron un tamaño medio de $964 \pm 85 \mathrm{x}$ $1.737,5 \pm 165 \mu \mathrm{m}$. La longitud media de los rizoides en esta etapa fue de $354,5 \pm 61 \mu \mathrm{m}$. Los gametófitos adultos fueron desnudos.

En la fase sexual se observaron dos tipos de gametófitos, unos bisexuales, con arquegonios típicos localizados bajo la escotadura (Fig. 3F) y anteridios en la base, y otros masculinos (Fig. 3G). Tanto los arquegonios como los anteridios observados en ambas formas fueron típicos. En primer lugar se desarrollaron protalos arquegoniados, y algunos gametófitos presentaron arquegonios a los 62 días. Aproximadamente 9 días después, los gametófitos que se encontraban en las proximidades de los gametófitos arquegoniados comenzaron a desarrollar gran cantidad de anteridios por toda su superficie. A los 88 días se registró el desarrollo de anteridios en la base de los gametófitos que hasta ese momento eran unisexuales femeninos y, por lo tanto, pasaron a ser bisexuales. En la fase sexual se observó una diferencia notable entre el tamaño de los gametófitos bisexuales, los que presentaron un tamaño medio de $2.450 \pm 190 \times 5.250 \pm 365 \mu \mathrm{m}$, y el de los gametófitos masculinos, cuyo tamaño medio fue de $1.938 \pm 115 \times 2.582 \pm 195 \mu \mathrm{m}$. A los 110 días tras la siembra, las poblaciones de gametófitos estaban constituidas por un 

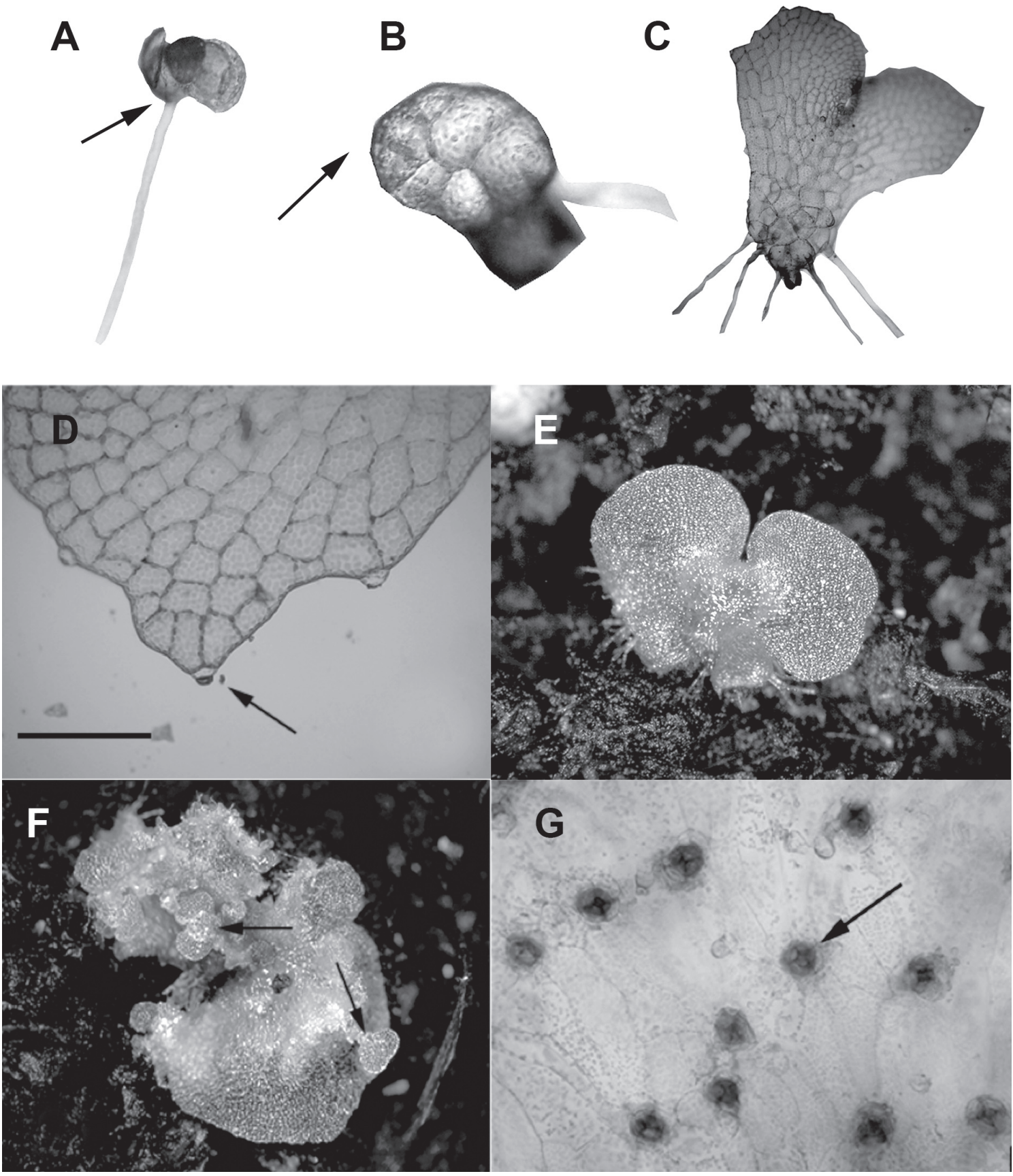

Figura 2. Patrón de desarrollo morfológico y caracteres principales de los gametófitos de Blechnum arcuatum. A) Germinación de la espora, con la célula protálica perpendicular al primer rizoide (flecha), 9 días. B) Primeros estadios de la fase laminar, con la primera célula meristemática apical (flecha), 15 días. C) Forma cordada joven, con escotadura y alas, 27 días. D) Detalle de la aparición de un tricoma marginal (flecha), 30 días. E) Gametófito adulto, 50 días. F) Proliferaciones vegetativas (flechas), 70 días. G) Detalle de los arquegonios en un gametófito femenino (flecha), 79 días. Barra $=100 \mu \mathrm{m}$ en A; $210 \mu \mathrm{m}$ en B; $450 \mu \mathrm{m}$ en C; $80 \mu \mathrm{m}$ en D; $800 \mu \mathrm{m}$ en E; $720 \mu \mathrm{m}$ en F; $40 \mu \mathrm{m}$ en G. Días medidos tras la siembra.

Figure 2. Pattern of morphological development and main features of Blechnum arcuatum gametophytes. A) Spore germination, with a prothallial cell emerging perpendicularly to the first rhizoid (arrow), 9 days. B) Early stages of the laminar phase, showing the first meristematic apical cell (arrow), 15 days. C) Juvenile cordate gametophyte, with the wings and notch, 27 days. D) Detail of marginal trichome development (arrow), 30 days. E) Adult gametophyte, 50 days. F) Vegetative proliferations (arrows), 70 days. G) Details of archegonia in a female gametophyte (arrow), 79 days. Bar $=100 \mu \mathrm{m}$ in A; $210 \mu \mathrm{m}$ in B; $450 \mu \mathrm{m}$ in C; $80 \mu \mathrm{m}$ in D; $800 \mu \mathrm{m}$ in E; $720 \mu \mathrm{m}$ in F; $40 \mu \mathrm{m}$ in G. Days after sowing. 

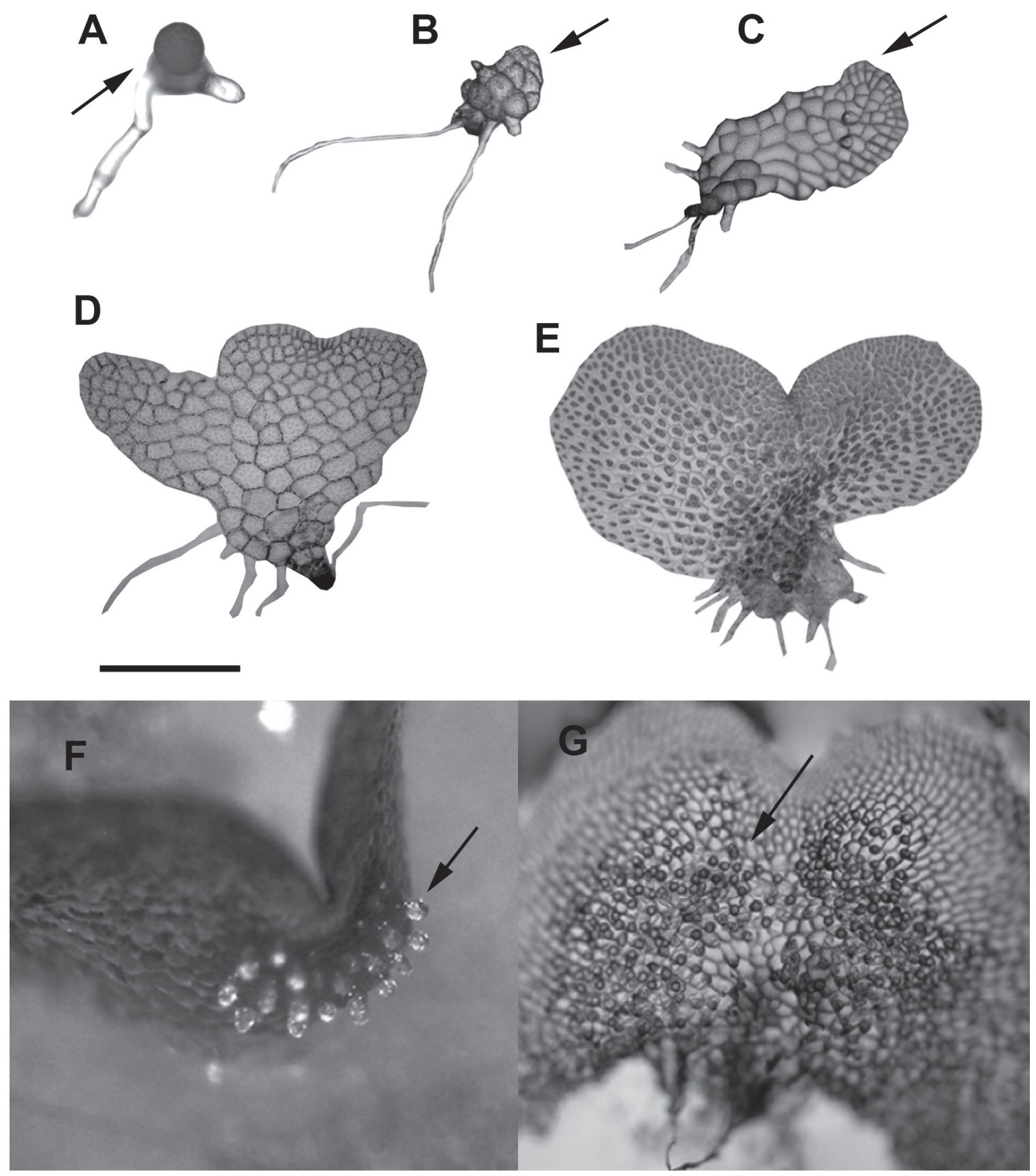

FiguRa 3. Patrón de desarrollo morfológico y caracteres principales de los gametófitos de Pteris semiadnata. A) Germinación de la espora, con la célula protálica perpendicular al primer rizoide (flecha), 10 días. B) Establecimiento de una célula meristemática subcónica apical (flecha), 20 días. C) Gametófito en fase laminar, con formación de un meristema pluricelular lateral (flecha), 30 días. D) Gametófito adulto lobulado, 52 días. E) Gametófito adulto cordado, algo asimétrico, 60 días. F) Gametófito bisexual, mostrando arquegonios (flecha), 110 días. G) Gametófito masculino, densamente cubierto por anteridios (flecha), 110 días. Barra $=150 \mu \mathrm{m}$ en A; $230 \mu \mathrm{m}$ en B; $700 \mu \mathrm{m}$ en $\mathrm{C}$, E; $460 \mu \mathrm{m}$ en D, G; $420 \mu \mathrm{m}$ en F. Días medidos tras la siembra.

FIgURE 3. Pattern of morphological development and main features of Pteris semiadnata gametophytes. A) Spore germination, with a prothallial cell emerging perpendicularly to the first rhizoid (arrow), 10 days. B) Establishment of a subconical, apical meristematic cell (arrow), 20 days. C) Gametophyte in laminar phase, with development of a lateral multicellular meristem (arrow), 30 days. D) Lobular adult gametophyte, 52 days. E) Cordate adult gametophyte, somewhat asymmetric, 60 days. F) Bisexual gametophyte, showing archegonia (arrow), 110 days. G) Male gametophyte, densely covered with antheridia (arrow), 110 days. Bar $=150 \mu \mathrm{m}$ in A; $230 \mu \mathrm{m}$ in B; $700 \mu \mathrm{m}$ in $\mathrm{C}, \mathrm{E} ; 460 \mu \mathrm{m}$ in $\mathrm{D}, \mathrm{G} ; 420 \mu \mathrm{m}$ in F. Days after sowing. 
$83 \%$ de gametófitos masculinos y un $17 \%$ de gametófitos bisexuales. Los gametófitos bisexuales adoptaron forma cordada al igual que los masculinos, pero en estos últimos, las alas no presentaron el margen liso como en el caso de los bisexuales, sino que el margen fue sinuoso.

En esta especie también se desarrollaron proliferaciones de naturaleza vegetativa.

\section{DISCUSIÓN}

La germinación de ambas especies es de tipo Vittaria, que es el patrón de germinación más común en los helechos homospóricos (Nayar \& Kaur 1971). El tiempo transcurrido entre la siembra y la primera germinación; la variación en el tiempo de los porcentajes de germinación, y los máximos de germinación alcanzados, se encuentran dentro de valores normales para los helechos homospóreos (Gabriel y Galán \& Prada 2010, Gabriel y Galán et al. 2015) considerando la edad de las esporas. La fase filamentosa de $B$. arcuatum fue muy efímera, hecho que se ha observado en otros gametófitos del género, como $B$. chilense (Kaulf.) Mett. y B. cycadifolium J.W. Sturm, en los que los filamentos estaban constituidos por 2-4 células (Pérez-García et al. 1996). En el caso de B. arcuatum los filamentos presentaron entre 3-4 células, lo que ocasionó que en principio se formaran gametófitos espatulados con un número de células muy reducido, hecho también observado en algunas otras especies de Blechnum (PérezGarcía et al. 1996). Los gametófitos adultos de B. arcuatum fueron cordados y presentaron pelos marginales y algunos superficiales, lo que ha sido reportado como un carácter general para los gametófitos de la familia Blechnaceae (Atkinson 1973), y detectado previamente en especies como B. sprucei C. Chr. (Gabriel y Galán et al. 2008), B. occidentale L., B. polypodioides Raddi (Mendoza \& Pérez-García 2009) y B. serrulatum Rich. (Rolleri et al. 2010). El patrón de desarrollo morfológico de $B$. arcuatum se corresponde (al igual que el resto de especies mencionadas) con el tipo Aspidium (Nayar \& Kaur 1969), característica muy frecuente en las especies de Blechnum, con excepción de algunas especies australianas y chilenas que no presentan pelos, como es el caso de $B$. chilense y B. penna-marina (Poir.) Kuhn, cuyo patrón de desarrollo morfológico es de tipo Adiantum (Nayar \& Kaur 1971, Mendoza \& Pérez-García 2009).

La fase filamentosa de P. semiadnata no fue tan efímera como lo es en otras especies descritas, como por ejemplo $P$. berteroana, cuya duración se prolongó 3 días (Mendoza et al. 1997). En esta especie, el meristema se localizó en la parte lateral de la lámina, por lo que los protalos fueron asimétricos en el comienzo de la fase adulta, todo lo cual es definitorio del modelo de desarrollo tipo Ceratopteris (Nayar \& Kaur 1969). Con posterioridad se obtuvieron protalos cordados con un meristema bien establecido en la escotadura. La asimetría en las primeras fases del desarrollo de la fase adulta se ha observado en otras especies del género, como es el caso de P. berteroana, y P. grandifolia L. (Atkinson 1973), sin embargo, otras especies del género presentan una forma simétrica desde los inicios de la fase adulta como P. tremula R. Br., P. multifida Poir. (Atkinson 1973) y P. incompleta Cav. (Prada et al. 2008).

La reproducción vegetativa mediante la formación de gametófitos sobre la superficie de la lámina y en los márgenes, se ha observado en las dos especies. Este fenómeno de reproducción vegetativa es normal en los helechos (Nayar \& Kaur 1971), habiéndose detectado en otras especies de los géneros estudiados (Martínez 2010), y podría estar causado por el estrés (e.g., ecológico, fisiológico), o por la edad avanzada, hechos conocidos desde hace años (Raghavan 1989).

A pesar de que se afirma que la secuencia normal de expresión sexual en helechos homospóreos comienza con la formación de anteridios, y seguidamente de arquegonios (Stokey \& Atkinson 1952), originando protalos bisexuales, en casi todas las especies de Blechnum, los gametófitos son unisexuales (Gabriel y Galán et al. 2008, Mendoza \& Pérez-García 2009), y en todos ellos la aparición de protalos arquegoniados precedió a la de protalos anteridiados. En este estudio, la detección de gametófitos unisexuales femeninos en $B$. arcuatum parece acorde con toda esta información.

En el momento de la reproducción, los cultivos de $P$. semiadnata estaban constituidos por un $83 \%$ de gametófitos masculinos y un $17 \%$ de gametófitos bisexuales. Las proporciones de sexos, a pesar de ser la fase más corta del ciclo biológico, puede tener importantes consecuencias sobre la viabilidad de la población (Watkins et al. 2007b). En otras especies del género, como $P$. berteroana (Mendoza et al. 1997) y $P$. chilensis Desv. (Letelier \& Peñailillo 2007), aparecieron también gametófitos bisexuales y, al igual que en nuestro caso, los arquegonios precedieron a los anteridios. En estos trabajos no se indica la existencia de protalos unisexuales masculinos.

Nuestros resultados parecen indicar la existencia de un sistema de anteridiógeno producido por los gametófitos bisexuales, los cuales parecen inducir la masculinidad de los protalos que se encuentran en sus proximidades. El sistema de anteridiógeno es conocido desde hace tiempo en Pteris, incluyendo la influencia interespecífica de control sexual, como en los casos de $P$. vittata L. y $P$. incompleta (Prada et al. 2008). La presencia de anteridiógeno aumenta la adecuación biológica de los gametófitos arquegoniados al incrementar el número de gametófitos masculinos presentes en el medio (Wilson 1981). Entre los gametófitos bisexuales y masculinos se observó un notable dimorfismo sexual, siendo los bisexuales considerablemente más grandes. Esto puede estar de acuerdo con la idea de que el tamaño pequeño de los gametófitos masculinos se debe 
a la distribución de los recursos, que serían utilizados más para la reproducción que para el crecimiento (Naf 1956).

\section{AGRADECIMIENTOS}

Este trabajo ha sido posible en parte gracias a una estancia de investigación del Dr. Gabriel y Galán en la Universidad de Concepción (Chile), financiada con una beca de investigación de la Fundación Santander. El Dr. Gabriel y Galán desea expresar su gratitud a todo el personal de la Universidad de Concepción, por su apoyo y colaboración. Otra parte del trabajo se ha realizado gracias a la financiación de la Universidad Complutense de Madrid (Grupo de Investigación "Biodiversidad y Taxonomía de Plantas Criptógamas", UCM 910801).

\section{BIBLIOGRAFÍA}

AtKInSON, L.R. 1973. The gametophyte and family relationships. Botanical Journal of the Linnaean Society 67: 73-90.

AtKinson, L.R. \& A.G. Stokey. 1964. Comparative morphology of the gametophyte of homosporous ferns. Phytomorphology 14: 51-71.

Durán, M.L. \& E.R. DE LA Sota. 1996. Delayed sex expression of hybrid gametophytes in Blechnum. In: J.M. CAmus, M. Gibby \& R.J. Johns (eds.), Pteridology in Perspective, pp: 515. Royal Botanic Gardens, Kew, United Kingdom.

Dyer, A. 1979. The culture of fern gametophytes for experimental investigation. In: A. Dyer (ed.), The experimental biology of ferns, pp. 254-305. Academic Press, London, United Kingdom.

Edwards, M.E. \& J.H. Miller. 1972. Growth regulation by ethylene in fern gametophytes. III. Inhibition of spore germination. American Journal of Botany 59: 458-465.

Farrar, D.R., C. Dassler, J.E. Watkins \& C. Skelton. 2008. Gametophyte ecology. In: T.A. Ranker \& C.H. Hauffler (eds.), Biology and evolution of ferns and lycophytes, pp. 222-256. University Press, Cambridge, United Kingdom.

Gabriel y Galán, J.M., L.M. Passarelli, C. Prada \& C.H. ROLLERI. 2008. Sporophyte morphology and gametophyte development of the fern Blechnum sprucei (Pteridophyta: Blechnaceae). Revista de Biología Tropical 56: 20272040.

Gabriel y Galán, J.M. \& C. Prada. 2010. Pteridophyte spores viability. In: H. Fernández, A. Kumar \& M.A. Revilla (eds.), Working with ferns: issues and applications, pp. 193-205. Springer, New York, USA.

Gabriel y Galán, J.M., C. Prada, C. Martínez-Calvo \& R. LAhoz-Beltrá. 2015. A Gompertz regression model for fern spores germination. Anales del Jardín Botánico de Madrid 72: e15.

Huang, Y., S. Hsu, T. Hsieh, H. Chou \& W. Chiou. 2011. Three Pteris species (Pteridacae, Pteridophyta) reproduce by apogamy. Botanical Studies 52: 79-87.

KazmierczaK, C. 1999. A familia Blechnaceae (C. Presl) Copel. (Pteridophyta) no Rio Grande do Sul. Tesis (Grau do
Mestre), Universidade Federal do Rio Grande do Sul. Porto Alegre, Brasil, $153 \mathrm{pp}$.

Kramer, K., T. Chambers \& E. Hennipman. 1990. Blechnaceae. In: K. Kramer \& P. Green (eds.), The families and genera of vascular plants: I. Pteridophytes and Gymnosperms, pp. 60-67. Springer, Berlin, Germany.

Letelier, L. \& P. Peñailillo. 2007. Desarrollo del gametofito y esporofito joven de Pteris chilensis Desv. (PteridaceaePteridophyta). Gayana Botánica 64: 93-97.

Lindsay, S. \& A. Dyer. 1990. Fern spore banks: implications for gametophyte establishment. In: J. Rita (ed.), Taxonomía, biogeografía y conservación de pteridófitos, pp. 243-253. Sociedad de Historia Natural de las Islas Baleares, Palma de Mallorca, Spain.

MartíneZ, O.G. 2010. Gametophytes and young sporophytes of four species of the fern genus Pteris (Pteridaceae) naturalized in the American continent. Revista de Biología Tropical 58: 89-102.

Mehltreter, K., L.R. Walker \& J.M. Sharpe. 2010. Fern ecology. Cambridge University Press, Cambridge. 460 pp.

Mendoza, A. \& B. Pérez- García. 2009. Morphogenesis of the gametophytes of eight Mexican species of Blechnum (Blechnaceae). Acta Botánica Mexicana 88: 59-72.

Mendoza, A., B. Pérez-García, I.R. Jaramillo \& M. Ricci. 1997. Gametophytic development in Pteris berteroana (Pteridaceae: Pterideae). Revista de Biología Tropical 45: 51-57.

Moran, R.C. 1995. Pteridaceae. In: G. Davidse, M. Souza \& S. Knapp (eds.), Flora Mesoamericana I, Psilotaceae a Salviniaceae, pp. 104-145. Universidad Autónoma de México, Missouri Botanical Garden \& The Natural History Museum (London), México D.F., México.

NAF, U. 1956. The demonstration of a factor concerned with the initiation of antheridia in polypodiaceous ferns. Growth 20: 91-105.

NAYAR, B.K. \& S. KaUR. 1968. Spore germination in homosporous ferns. Journal of Palynology 4: 1-14.

NAYAR, B.K. \& S. KaUR. 1969. Types of prothallial development in homosporous ferns. Phytomorphology 19: 179-188.

Nayar, B.K. \& S. Kaur. 1971. Gametophytes of homosporous ferns. The Botanical Review 37: 295-396.

Pérez-García, B., A. Mendoza \& M. Ricci. 1996. Morphogenesis of the sexual phase in Blechnum chilense and Blechnum cycadifolium (Pterophyta: Blechnaceae). Revista de Biología Tropical 44: 491-497.

Prada, C., V. Moreno \& J.M. Gabriel y Galán. 2008. Gametophyte development, sex expression and antheridiogen system in Pteris incompleta Cav. (Pteridaceae). American Fern Journal 98: 14-25.

Puspitasari, D.S., T. Chikmawati \& T.N. Praptosuwiryo. 2015. Gametophyte Morphology and Development of Six Species of Pteris (Pteridaceae) from Java Island Indonesia. Journal of Tropical Life Science 5: 98-104.

Raghavan, V. 1989. Developmental biology of fern gametophytes. University Press, Cambridge. 362 pp.

Rodríguez-Ríos, R. 1973. Morfología de los protalos y esporofitos jóvenes de algunas especies chilenas de Blechnum (Polypodiaceae s.1.). Gayana Botánica 22: 1-30.

Rodríguez-Ríos, R. 1995a. Blechnaceae. En: C. Marticorena \& R. Rodríguez (eds.), Flora de Chile, Vol. 1, pp. 286-303. 
Universidad de Concepción, Concepción, Chile.

Rodríguez-Ríos, R. 1995b. Pteridaceae. En: C. Marticorena \& R. Rodríguez (eds.), Flora de Chile, Vol. 1, pp. 213-218. Universidad de Concepción, Concepción, Chile.

Rolleri, C. \& C. Prada. 2006. Catálogo comentado de las especies de Blechnum (Blechnaceae-Pteridophyta) de Mesoamérica y Sudamérica. Anales del Jardín Botánico de Madrid 63: 67-106.

Rolleri, C., C. Prada, J.M. Gabriel y Galán, L.M. Passarelli \& M.M. Ciciarelli. 2010. Morphology of the sporophyte and gametophyte of the swamp fern, Blechnum serrulatum (Blechnaceae, Pteridophyta). Australian Journal of Botany 58: 508-518.

Schneller, J. 2008. Antheridiogens. In: T.A. Ranker \& C.H. Hauffler (eds.), Biology and evolution of ferns and lycophytes, pp. 134-158. University Press, Cambridge, United Kingdom.

Stokey, A.G. \& L.R. Atrinson. 1952. The gametophyte of Blechnum spicant (L.) Wither and B. buchtienii Rosenst. Phytomorphology 2: 9-15.

Vicent, M., J.M. Gabriel y Galán \& A. Ainouche. 2014. Insight into fern evolution: a mechanistic approach to main concepts and study techniques. Botanica Complutensis 38 : 7-24.

WADA, M. 2008. Photoresponses in fern gametophytes. In: T.A.
Ranker \& C.H. Hauffler (eds.), Biology and evolution of ferns and lycophytes, pp. 3-48. University Press, Cambridge, United Kingdom.

WARNE, T. \& R. LLOYD. 1980. The role of spore germination and gametophyte development in habitat selection: temperature response in certain temperate and tropical ferns. Bulletin of the Torrey Botanical Club 107: 57-64.

Watkins, J.E., M.C. Mack, T.R. Sinclair \& S.S. Mulkey. 2007a. Ecological and evolutionary consequences of desiccation tolerance in tropical fern gametophytes. New Phytologist 176: 708-717.

Watkins, J.E., M.K. Mack \& S.S. Mulkey. 2007b. Gametophyte ecology and demography of epiphytic and terrestrial tropical ferns. American Journal of Botany 94: 701-708.

WhitTier, D. P. 1970. Rate of gametophyte maturation in sexual and apogamous species of ferns. Phytomorphology 20: 3035.

WiLson, M.F. 1981. Sex expression in fern gametophytes: some evolutionary possibilities. Journal of Theoretical Biology 93: 403-409.

Zhang, K.M., L. Shi, X.C. Zhang, C.D. Jiang \& W.L. Tim-Chun. 2008. Gametophyte Morphology and Development of Six Chinese Species of Pteris (Pteridaceae). American Fern Journal 98: 33-41.

Recibido: 05.10 .15

Aceptado: 18.07.16 